\title{
A Right Sternalis Muscle: Clinical and Surgical Significance
}

\author{
Aguado-Henche $\mathrm{S}^{1 *}$, Clemente de Arriba $\mathrm{C}^{1}$ and Cristóbal-Aguado $\mathrm{S}^{2}$ \\ 1Professor, Teaching Unit of Human Anatomy and Embryology, Faculty of Medicine and \\ Health Sciences, University of Alcalá, Spain \\ 2Nurse Practitioner, "La Paz" University Hospital, National Health System, Spain
}

\section{Case Report}

Volume 2 Issue 2

Received Date: May 30, 2018

Published Date: June 01, 2018

*Corresponding author: Dr. Soledad Aguado-Henche, Professor, University of Alcalá, Madrid, Spain, Teaching Unit of Human Anatomy and Embryology, Department of Surgery, Medical and Social Sciences, Faculty of Medicine and Health Sciences, Ctra Madrid-Barcelona - Km 33600, E-28805 Alcalá de Henares (Madrid), Spain, Tel: 3491885 4539; Email: soledad.aguado@uah.es

\section{Abstract}

A supernumerary muscle mass corresponding to a right sternalis muscle was found in the anterior chest wall of a 67year-old Spanish female cadaver during a routine anatomical dissection class. The sternalis muscle is unknown for many medicine and health sciences undergraduate students because it is not included in basic texts on human anatomy. Consequently, this muscle is often unknown even in clinical practice and, in most cases, it is found in a living subject during radiological examination (sometimes leading to diagnostic error) or during thoracic surgery. In the latter case, it may be used for reconstruction in plastic surgery.

This paper intends to bring attention to this muscle, which, despite being an infrequent anatomical variation, is not rare, and to raise awareness about its clinical importance. It is, therefore, crucial to know about its possible presence in the human body.

Keywords: Sternalis muscle; Pectoralis major; Anatomical variation; Chest wall; Embalmed cadaver

\section{Introduction}

The sternalis muscle is a small inconstant muscle located in the anterior thoracic wall, superficial to the pectoralis major and the sternum. It was first reported by Bartolomeu Cabrolio in his book Anatomes Elenchus Accuratissimus in 1604. Du Puy described it with more detail in 1726. In 1867, Turner [1] provided a very detailed description of the muscle and classified it according to its format within the human body. He even found similarities with the cutaneous pectoris of lower vertebrates. Later, Jelev [2] published a review regarding the prevalence of the muscle in various populations and introduced a classification based on its morphology and insertions. The sternalis muscle has received many different names: sternalis, episternalis, parasternalis, presternalies, rectus sternalis. Some authors suggest the nomenclature rectus thoracis, owing to its unique orientation in the anterior thoracic wall and its continuity with the ventral longitudinal sheet of trunk muscle [3]. Nonetheless, nowadays, most of the scientific community uses the term "sternalis muscle" to refer to this anatomical structure. The present report corresponds to the incidental finding of a right sternalis muscle, which is 


\section{Journal of Human Anatomy}

presented due to its importance for daily clinical and surgical practice.

\section{Sternalis Muscle}

During a routine anatomical dissection class that was part of the undergraduate curriculum in medical college, a supernumerary muscle mass corresponding to a sternalis muscle was found in the thoracic region. The muscle belonged to a 67-year-old Caucasian female cadaver from the Human Anatomy and Embryology Laboratory of the Department of Surgery and Medical and Social Sciences of the University of Alcalá, in Alcalá de Henares (Madrid, Spain). The cadaver was fixed with the new conservation technique Green $\mathrm{Fix}^{\circledR}{ }^{\circledR}$ (a new formaldehyde-free fixative. It is a colourless, non-toxic solution, suitable for all kinds of tissue fixation, that allows for formalin replacement in laboratories). All dissections carried out in our laboratory meet the regulations approved by the Faculty of Medicine of the University of Alcalá. Following Testut's technique, and once the skin of the anterior thoracic wall had been removed, a muscle appeared in the right hemithorax, with the fibres parallel to the lateral border of the sternum (parasternal location) and located underneath the subcutaneous tissue and in front of the pectoralis major's fascia (Figure 1). It was $8.5 \mathrm{~cm}$ long and $3 \mathrm{~cm}$ wide, measured by means of a Vernier calliper. The upper insertion lay on the right half of the sternal manubrium's anterior face and the inferior fibres inserted in the aponeurosis of the external abdominal oblique muscle. Both insertions involved very short aponeurotic fibres.

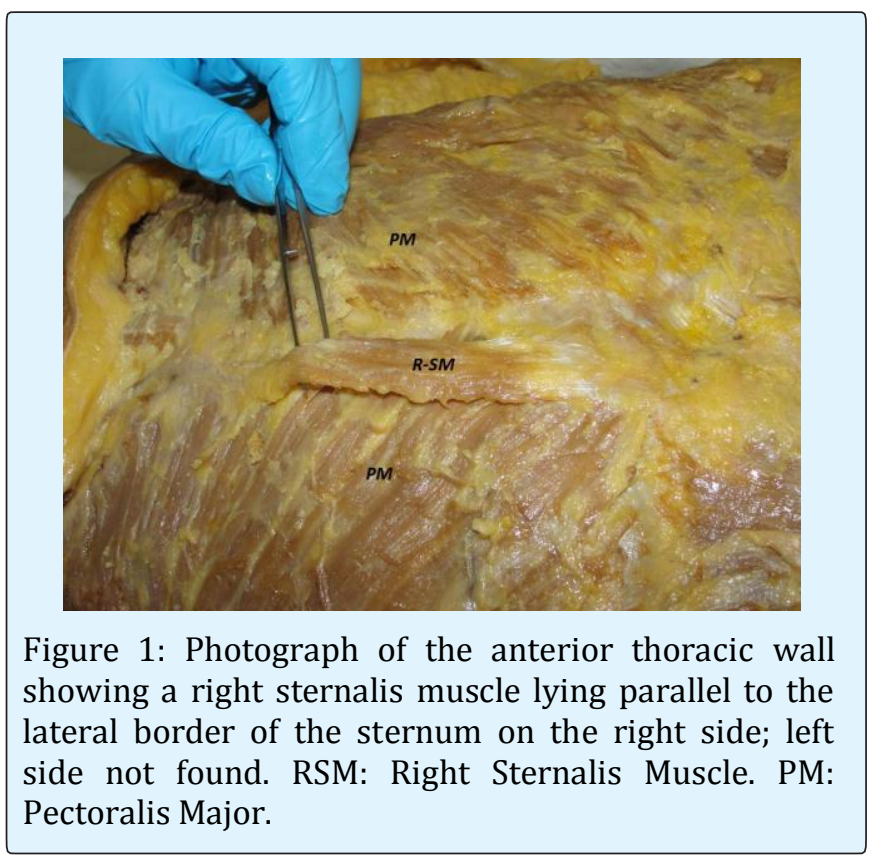

\section{Discussion}

The sternalis muscle is present in approximately $4 \%$ of the population $[2,4,5]$, although its prevalence is directly influenced by gender. According to the figures contained in the literature, its prevalence is higher in women than in men. This is our case and other authors' [6-9]. Regarding ethnic group, it is more frequent in Asian population [6], especially in Indian population [2].

The sternalis muscle found conforms to the morphological characteristics described by Jelev [2] for this muscle; it corresponds to the I1 type of their description (simple unilateral belly). Its format is similar to that reported by other authors in the literature: unilateral [3,10-14], fusiform [14], in the right hemithorax, in a parasternal position and with the fibres parallel to the sternum [15] and superficial to the pectoralis major and its fascia, its fibres not being in continuity with fibres of any other adjacent muscle [13]. The bilateral sternalis muscle is more uncommon $[8,11,16]$ and, in case it appears, it is usually asymmetric, with the right side better developed than the left one [17]. The most uncommon variation is a digastric sternalis muscle [18]. The presence of the muscle has been revealed during cadaveric dissection in medicine schools $[10-14,16,19-23]$ that are in the literature as case reports. Its presence is usually asymptomatic, although one symptomatic case with long-term pain in the parasternal region has been described [24]. It may even produce alterations in the external aspect of the thorax, such as breast asymmetry or deviation of the ipsilateral nippleareolar complex [25]. Moreover, the sternalis muscle can coexist with vascular variations of the kidney, the testicle or the adrenal gland, and even positive correlation with anencephaly in foetuses has been reported [26].

The unawareness of the possible existence of the muscle may lead to difficult clinical situations, such as simulation of a malignant neoplasm in the mammogram [5] or alterations in the electrocardiogram [27]. In the last few years, the muscle has been detected more frequently due to the advance in diagnostic imaging techniques, despite ultrasonography and mammography, used in the examination of patients with breast pathologies, not being able to detect the presence of the muscle [28]. Nevertheless, the magnetic resonance imaging (MRI) or the multidetector computed tomography, which are very widely used, can reveal it $[18,24]$. In many cases, it has been found during a radical mastectomy in breast cancer patients $[9,26]$. Moreover, the depth of the breast lymph nodes may vary due to the muscle's presence [5]. Once 
the muscle is found, its existence should be recorded in the patient's medical history [29].

In case of breast surgery, the surgeon may act differently depending on his/her awareness or not of the muscle's existence. When detected intraoperatively during breast surgery, it should ideally be removed together with the complete breast tissue [6,9], although some authors state that its removal will not improve the patient's prognosis or survival [28]. On the other hand, when detected before surgery, it can be used in oncoplastic surgical procedures as a muscular flap $[21,25]$. Although the function of this muscle may be trivial for some authors [22], others (while considering it unknown) suggest that it may work as an accessory muscle of inhalation, raising the lower part of the anterior thoracic wall and a few consider it useful in reconstruction surgery of the head and neck $[10,13,19,22,26]$.

There is still controversy about poorly known aspects of the sternalis muscle, such as its origin: some researchers, based on the innervations found (by the pectoral nerves), support the idea that it is a muscle derived from the pectoralis major [30], since the presence of the sternalis muscle is usually associated with an atypical development of the pectoralis major [16] or a partial absence of this muscle [13,31]. For others, it has its origin in the rectus abdominis if the innervation is supplied by the intercostal nerves [2,3]. In any case, it seems clear that the innervation derives from the intercostal nerves, the pectoral nerves or both $[13,14,19,26,31]$. For Jelev [2], vascularisation was supplied by perforating branches of the internal thoracic artery; however, in our case it was not tried to prove vascularisation or innervation, probably damaged when separating the muscle on its lateral margins. Nowadays, very few texts on medical education or human anatomy refer to the sternalis muscle [30,32-34]. Therefore, although anatomists are the professionals who know it most deeply, future practitioners and other health sciences students graduate without knowing about this muscle mass with important clinical and surgical implications, given the advance in surgical and diagnostic imaging techniques.

\section{Conclusion}

The presence of the sternalis muscle is revealed during dissection classes in medicine schools, when using diagnostic imaging techniques or during surgical procedures, mostly regarding breast pathologies. We aim to contribute to its knowledge by internists, gynaecologists, radiologists and surgeons. Practitioners must be aware of this possible anatomical variation in order to avoid diagnostic errors and the unnecessary use of other more bloody or aggressive diagnostic techniques for the patient.

Due to the possible consequences derived from the existence of the sternalis muscle, we propose that this muscle is not only mentioned, but described in detail in current texts on human anatomy, among others, in order to raise awareness about it also among health sciences undergraduate students.

\section{Acknowledgements}

The authors would like to thank medicine undergraduate students, who are the core of our educational efforts and the main incentive to continue doing research. They would like to give special thanks to all those persons who voluntarily donate their body to science. Many thanks. The authors declare no conflict of interest.

This article is the result of Teaching Innovation Project UAH / EV920. 2017/18.

\section{References}

1. Turner WM (1867) On the musculus sternalis. J Anat Physiol 1(2): 246-253.

2. Jelev L, Georgiev G, Surchev L (2001) The sternalis muscle in the Bulgarian population: classification of sternales. J Anat 199(Pt 3): 359-363.

3. Mehta V, Arora J, Yadav Y, Suri RK, Rath G (2010) Rectus thoracis bifurcalis: a new variant in the anterior chest wall musculature. Rom J Morphol Embryol 51(4): 799-801.

4. Pró E (2012) Anatomía Clínica. 1ªt (Edn.), Buenos Aires: Médica Panamericana.

5. Poveda CA, Muñoz EJ, Camargo DC (2013) Músculo esternalis: variante anatómica que simula neoplasia en mamografía. Revista colombina de cancerología 17(1): 46-49.

6. Kabay B, Akdogan I, Ozdemir B, Adiguzel E (2005) The left sternalis muscle variation detected during mastectomy. Folia Morphol (Warsz) 64(4): 338-340. 
7. Hung LY, Lucaciu OC, Wong JJ (2012) Back to the debate: sternalis muscle. Int J Morphol 30(1): 330336.

8. Cherian SB, Gandhalam AJ (2014) Rectus sternalis muscle: An anatomical variant of anterior chest wall. OA Anatomy 2(2): 16.

9. Sasmal PK, Meher S, Mishra TS, Deep N, Prabhas R, et al. (2015) Sternalis Muscle: An Unexpected Finding during Mastectomy. Hindawi Publishing Corporation. Case Rep Surg.

10. Arráez-Aybar LA, Sobrado Pérez J, Mérida-Velasco JR (2003) Left Musculus Sternalis. Clin Anat 16(4): 350354.

11. Preeti T, Harsha B, Ujwal G, Sthapak E, Bharti S, et al. (2012) The bilateral sternalis: an uncommon anatomical variant. J Clin Diagn Res 6(5): 767-769.

12. Silveira D, Sousa LM, Siqueira SL, Oliveira BVM, Silva AT, et al. (2012) Sternalis muscle: ana anatomic variation of the anterior chest wall. J Morphologycal Sci 29(2): 76-78.

13. Katara P, Chauhan S, Arora R, Pankaj S (2013) A Unilateral Rectus Sternalis Muscle: Rare But Normal Anatomical Variant of Anterior Chest Wall Musculature. J Clin Diagn Res 7(12): 2665-2667.

14. Pillay M, Ramakrishnan S, Mayilswamy M (2016) Two Cases of Rectus Sternalis Muscle. J Clin Diagn Res 10(1): AD01-AD03.

15. Raikos A, Paraskevas GK, Tzica M, Faustmann P, Triaridis S, et al. (2011) Sternalis muscle: an underestimated anterior chest wall anatomical variant. J Cardiothorac Surg 6: 73.

16. O’Neil MN, Folan Curran J (1998) Case report: bilateral sternalis muscles with a bilateral pectoralis major anomaly. J Anat 193(2): 289-292.

17. Vaithianathan G, Aruna S, Rajila RHS, Balaji T (2011) Sternalis "mystery" muscle and its clinical implications. Ital J Anat Embryol 116(3): 139-143.

18. Guru A, D'souza M, Kumar N, Nayak SB, Patil J, et al. (2013) A digastric sternalis muscle: a rare finding. OA Case Reports 2(17): 163.
19. Kumar MRB, Bhagath KP, Siddaraju G (2009) Sternalis muscle revisted in South Indian male cadaver: a case report. Cases J 2: 6318.

20. Zaher WA, Darwish HH, Abdalla AME, Saeed MV, Mujahid MK (2009) Sternalis: a clinically important variation. Pak J Med Sci 25(2): 325-328.

21. Raikos A, Paraskevas GK, Yusuf F, Kordali P, Ioannidis 0 , et al. (2011) Sternalis muscle: a new crossed subtype, classification, and surgical applications. Ann Plast Surg 67(6): 646-648.

22. Vishal K, Kavitha K, Vinay KV, Raghavendra AY (2013) Unilateral rectus sternalis muscle: a case report. Nitte University J Health Sci 3(1): 66-68.

23. Bharathi D, Sarala HS, Padmalatha N, Balakrishna (2014) Morphology of rectus sternalis: a cadaveric study. Int J Life Sci Res 2(4): 65-67.

24. Gruber L, Martinoli C, Tagliafico AS, Gruber J, Klauser AS, et al. (2016) A rare case of a symptomatic sernalis muscle: ultrasonograpy and MRI correlation. Ultrasound Int Open 2(4): E140-E141.

25. Khan UD (2008) Use of the Rectus Sternalis in Augmentation Mammoplasty: Case Report and Literature Search. Aesthet Plast Surg 32(1): 21-24.

26. Harish K, Gopinath KS (2003) Sternalis muscle: inportance in surgery of the breast. Surg Radiol Anat 25(3-4): 311-314.

27. Glasser SP (1975) Electrocardiogram of the month. J Lousiana State M Soc 127: 136-150.

28. Kocaay F, Basceken SI, Akyol C, Toygar S, Utku C, et al. (2014) The importance of Sternalis Muscle in Breast Surgery. Anat Physiol 4(4): 160.

29. Mier-García JF, López Subias J, Peña Tobar CE, Baena Caldas GP (2016) Supernumerary muscular masses of the anterior thoracic Wall. Case report and review. Rev Fac Cien Med Cordoba 73(4): 291-296.

30. Bannister LH, Berry M, Collins P (1995) Gray's Anatomy, 38th edn, p.838. New York, Edinburgh, London, Tokyo, Madrid and Melbourne: Churchill Livingstone.

31. Kida MY, Kudoh H (1991) Innervation of the sternalis muscle accompanied by congenital partial absence of 


\section{Journal of Human Anatomy}

the pectoralis major muscle. Okajimas Folia Anat Jpn 67(6): 449-55.

32. Last RJ (1972) Last's Anatomy-Regional and Applied, $5^{\text {th }}$ (Edn.), Churchill Livingstone: Edinburgh, pp: 82.
33. Loukas M, Bowers M, Hullett J (2004) Sternalis muscle: a mystery still. Folia Morphol (Warsz), 63(2): 147-149.

34. Simhadri D, Suseelamma D, Praveen Kumar M (2012) Uncommon Variation in Musculature of the Chest wall. Anat Physiol 2: 113. 